\title{
A line-of-sight electron cyclotron emission receiver for electron cyclotron resonance heating feedback control of tearing modes
}

Oosterbeek, J.W.; Bürger, A.; Westerhof, E.; de Baar, M.R.; van den Berg, M.A.; Bongers, W.A.;

Graswinckel, M.F.; Hennen, B.A.; Kruijt, O.G.; Thoen, J.

Total number of authors:

14

Published in:

Review of Scientific Instruments

Link to article, DOI:

$10.1063 / 1.2976665$

Publication date:

2008

Document Version

Publisher's PDF, also known as Version of record

Link back to DTU Orbit

Citation (APA):

Oosterbeek, J. W., Bürger, A., Westerhof, E., de Baar, M. R., van den Berg, M. A., Bongers, W. A., Graswinckel, M. F., Hennen, B. A., Kruijt, O. G., Thoen, J., Heidinger, R., Korsholm, S. B., Leipold, F., \& Nielsen, S. K. (2008). A line-of-sight electron cyclotron emission receiver for electron cyclotron resonance heating feedback control of tearing modes. Review of Scientific Instruments, 79(9), 093503. https://doi.org/10.1063/1.2976665

\section{General rights}

Copyright and moral rights for the publications made accessible in the public portal are retained by the authors and/or other copyright owners and it is a condition of accessing publications that users recognise and abide by the legal requirements associated with these rights.

- Users may download and print one copy of any publication from the public portal for the purpose of private study or research.

- You may not further distribute the material or use it for any profit-making activity or commercial gain

- You may freely distribute the URL identifying the publication in the public portal 


\title{
A line-of-sight electron cyclotron emission receiver for electron cyclotron resonance heating feedback control of tearing modes
}

\author{
J. W. Oosterbeek, ${ }^{1}$ A. Bürger, ${ }^{1}$ E. Westerhof,${ }^{2}$ M. R. de Baar, ${ }^{2}$ M. A. van den Berg, ${ }^{2}$ \\ W. A. Bongers, ${ }^{2}$ M. F. Graswinckel, ${ }^{2}$ B. A. Hennen, ${ }^{2}$ O. G. Kruijt, ${ }^{2}$ J. Thoen, ${ }^{2}$ \\ R. Heidinger, ${ }^{3}$ S. B. Korsholm, ${ }^{4}$ F. Leipold, ${ }^{4}$ and S. K. Nielsen ${ }^{4}$ \\ ${ }^{1}$ Forschungszentrum Jülich $\mathrm{GmbH},{ }^{\mathrm{a}}$ Institut für Energieforschung-Plasmaphysik, \\ Association EURATOM-FZJ, 52425 Jülich, Germany \\ ${ }^{2}$ FOM-Institute for Plasma Physics Rijnhuizen, ${ }^{\mathrm{b}}$ Association EURATOM-FOM, \\ Trilateral Euregio Cluster, postbus 1207, 3430 BE Nieuwegein, The Netherlands \\ ${ }^{3}$ Forschungszentrum Karlsruhe, Institut für Materialforschung I, Association EURATOM-FZK, \\ P.O. Box 3640, D-76021 Karlsruhe, Germany \\ ${ }^{4}$ EURATOM-Risф National Laboratory for Sustainable Energy, Technical University of Denmark, \\ DK-4000 Roskilde, Denmark
}

(Received 11 June 2008; accepted 8 August 2008; published online 8 September 2008)

\begin{abstract}
An electron cyclotron emission (ECE) receiver inside the electron cyclotron resonance heating (ECRH) transmission line has been brought into operation. The ECE is extracted by placing a quartz plate acting as a Fabry-Perot interferometer under an angle inside the electron cyclotron wave (ECW) beam. ECE measurements are obtained during high power ECRH operation. This demonstrates the successful operation of the diagnostic and, in particular, a sufficient suppression of the gyrotron component preventing it from interfering with ECE measurements. When integrated into a feedback system for the control of plasma instabilities this line-of-sight ECE diagnostic removes the need to localize the instabilities in absolute coordinates. (C) 2008 American Institute of Physics. [DOI: 10.1063/1.2976665]
\end{abstract}

\section{INTRODUCTION}

The principle route to the development of fusion power plants is formed by tokamak devices. In a tokamak the plasma is confined by magnetic fields forming closed toroidal magnetic surfaces. ${ }^{1,2}$ In order to make the fusion process economically viable the ratio of the magnetic pressure over the plasma pressure needs to be sufficiently high. This ratio is expressed by the normalized parameter $\beta=2 \mu_{0} p / B^{2}$, where $p$ is the plasma pressure and $B$ the magnetic field. At these high values of $\beta$, however, various instabilities are found to occur. For example, neoclassical tearing modes (NTMs) are created once $\beta$ exceeds a certain threshold. ${ }^{3}$ These modes form magnetic islands through the reconnection of magnetic field lines on opposite sides of resonant surfaces. Because the heat and particle transport along magnetic field lines is very fast, this leads to increased radial transport of energy and decreased confinement, and causes a flattening of the temperature and pressure profiles across the magnetic islands. ${ }^{3}$ This flattening of the pressure profile inside the island leads to the loss of the neoclassical, pressure driven bootstrap current in the islands, which is responsible for nonlinear destabilization of the mode. NTMs are characterized by their poloidal and toroidal mode numbers $m$ and $n$, respectively. In addition to the reduced confinement caused by NTMs, the $m=2, n=1$ NTM is often seen to lead to disruptive termination of the discharge. Stable and safe plasma operation of high $\beta$ fusion reactors therefore requires proper control of NTMs.

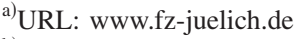

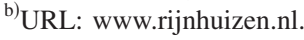

The most promising method of NTM control is by means of high power electron cyclotron waves (ECWs). ${ }^{4} \mathrm{Ab}$ sorption of these waves as well as electron cyclotron emission (ECE) occurs in the region where the wave frequency is resonant with the electron cyclotron frequency or one of its harmonics, i.e., $f=n f_{c e}=n q B /(2 \pi m)$, with $n=1,2, \ldots, q$ the electron charge, $m$ the electron mass, and $B$ the magnetic field. In tokamaks, the magnetic field is typically of the order of several tesla so that one is dealing with frequencies of the order of $100 \mathrm{GHz}$. At these frequencies a wave beam can be focused down to a few centimeters, such that the power will be absorbed/emitted from a well localized region in the plasma. A movable launching mirror can be used to steer the beam such that its intersection with the resonance plane is at a desired location. The suppression of NTMs by high power ECW has been demonstrated, for example, on ASDEX-Upgrade, ${ }^{5}$ JT-60U, ${ }^{6}$ and DIII-D. ${ }^{7}$ Suppression of NTMs by ECW is achieved by replacing the missing bootstrap current inside the island by currents driven by the ECW power. These currents may either be driven directly through electron cyclotron current drive (ECCD) or may be generated inductively through peaking of the temperature profile inside the island as a consequence of electron cyclotron resonance heating (ECRH). The suppression of NTMs can only work if the current is added at the precise location where the "hole" in the bootstrap current exists, i.e., inside the magnetic island. As generally the plasma and the islands are rotating, this means that the ECW power must not only be placed at the precise location of the island but also must be timed such that the power is only deposited at the island $O$-point, i.e., where the island has its maximum width. Power deposited 
around the island $X$-point, where the separatix of the island is, is at best wasted, but can also lead to further destabilization of the mode. Recent experiments on ASDEX-Upgrade have confirmed the advantage for NTM suppression from modulation of the ECW power in the proper phase of the island rotation. ${ }^{8}$ Effective and efficient control of NTMs thus requires accurate localization, and modulation of the $\mathrm{ECW}$ power.

NTMs can be detected by monitoring the electron temperature as measured by ECE or by monitoring perturbations on the magnetic field at the plasma edge through the Mirnov coils. The flattening of the temperature profile across the rotating magnetic island leads to fluctuations in the electron temperature, which reveal the presence of the island and its precise location in the ECE spectrum through the characteristic $180^{\circ}$ phase jump between adjacent channels on opposite sides of the resonant surface. This also allows the determination of the phase of the mode. The absolute coordinates are found by mapping of the ECE spectrum onto an equilibrium reconstruction of the plasma. In case the Mirnov coil signals are available, the poloidal and toroidal mode numbers of the mode can be identified through the proper combination of different coils. The subsequent radial localization of the mode then requires knowledge about the location of the resonant surfaces from magnetic equilibrium reconstructions.

A computation of the proper launching angle for the ECW power not only requires the precise location of the mode but also the full plasma equilibrium in order to be able to account for the effects of refraction of the ECW beam. In summary, implementation of a real time control scheme of NTMs by ECCD or ECRH requires much more input data than detection of the mode alone: it also requires real time computation of the plasma profiles and the magnetic equilibrium. All these measurements are prone to errors, which cause errors in the computed launching angle and may result in power deposition outside the required range. A control system based on line-of-sight detection of the modes ${ }^{9,10}$ considerably reduces the number of measurements and computations, making it much more simple and robust. In this scheme the ECW launcher is used as antenna to feed an ECE spectrum centered around the gyrotron frequency through the ECW transmission line into a radiometer. The ECE spectrum is scanned for the presence of a mode, and if found the launcher is moved such that the location of the power deposition coincides with the location of the island. This ensures that the ECW power is deposited at the exact center of the mode, without the need to compute absolute coordinates, or requiring knowledge of the plasma equilibrium.

This is an elegant solution but there is a catch. The forward power in the ECW transmission line is in the order of a megawatts, while the reverse ECE power is typically in the nanowatts range. The coupling element in the transmission line must thus be capable of separating power levels that differ by 15 orders of magnitude! Two aspects can be exploited to overcome this problem: (i) the waves to be separated travel in opposite direction, and (ii) the gyrotron frequency itself needs not to be present in the required ECE spectrum. What is required is a frequency selective direc-

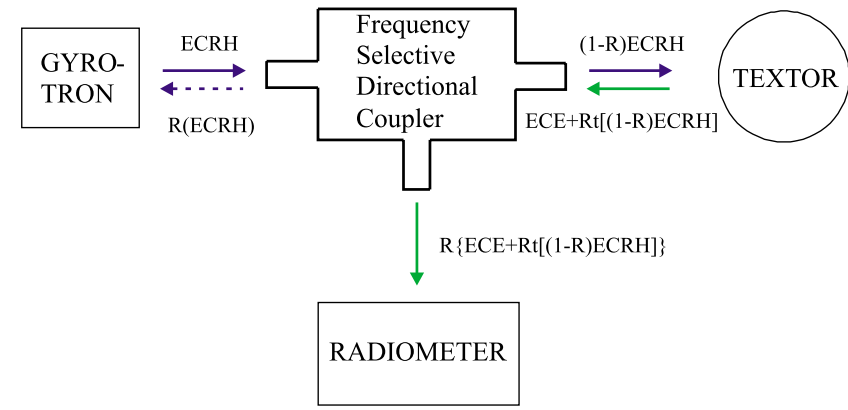

FIG. 1. (Color online)_Schematic of the frequency selective directional coupler. $R$ is the frequency dependent reflected fraction of power of the directional coupler: low for the gyrotron frequency, and high for the ECE frequencies of interest. $R_{t}$ is the fraction of ECW power returning from TEXTOR. Note that losses in the coupler, and reflections from TEXTOR to the gyrotron, have been left out.

tional coupler, transparent to the gyrotron frequency, but reflective for the ECE frequencies of interest as illustrated in Fig. 1.

The ECRH installation at the TEXTOR tokamak ${ }^{11}$ is well suited to implement a pilot scheme of a line-of-sight feedback system. The ECRH installation consists of a 140 $\mathrm{GHz}, 800 \mathrm{~kW}, 10 \mathrm{~s}$ gyrotron with steerable launcher. ${ }^{12}$ At the TEXTOR tokamak a set of perturbation coils, the so called dynamic ergodic divertor (DED) ${ }^{13}$ allows to induce tearing modes in a controlled way. Islands can be driven in the plasma using the DED, or by programming discharges that produce natural tearing modes. The ECRH installation allows to deposit ECW with an accuracy of a few percent of the minor radius, and if required, modulated as a function of time to only heat during the $O$-point phase of the island.

The line-of-sight system may not only be used for the feedback control of NTMs but also for other applications which require the precise localization of the ECW power relative to a feature in the plasma that can be identified in an ECE spectrum. Another example is the control of sawteeth which requires ECCD on either side of the sawtooth inversion radius depending on the desired effect: co-ECCD leading to sawtooth (de)stabilization when deposited just (inside) outside the inversion radius. ${ }^{14,15}$ Application of the line-ofsight feedback scheme for manipulation of sawteeth is also being explored.

This paper is organized as follows. In Sec. II the system requirements are defined by analyzing the detection and localization of modes in TEXTOR. Section III describes the choices that were made in the design of the instrument and the realization. This is followed in Sec. IV by performance tests of the instrument. In Sec. V first results are presented. This paper is concluded in Sec. VI by a summary, discussion of results, and an outlook.

\section{SYSTEM REQUIREMENTS}

The system requirements are set by the parameters of the TEXTOR tokamak ${ }^{11}$ and its ECRH system, ${ }^{12}$ and by the main tasks of the system: i.e., detection and localization of the magnetic islands associated with tearing modes, and determination of the phase of the island. The most important modes for stabilization are the $m=2, n=1$ and $m=3, n=2$ 
Flux surfaces and power deposition for $\mathrm{Bt}=2.25 \mathrm{~T}$ and $\mathrm{Ip}=350 \mathrm{kA}$

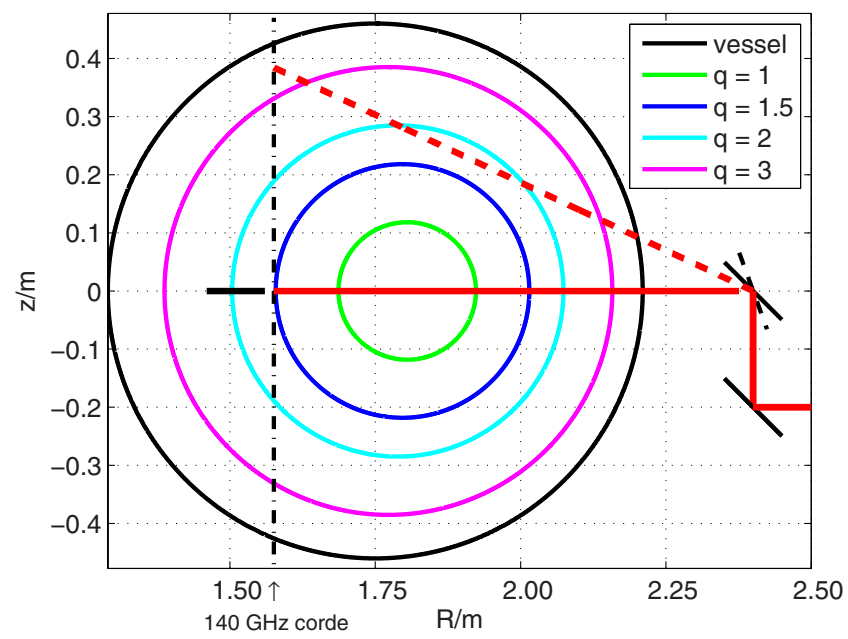

FIG. 2. (Color online)_Flux surfaces and power deposition for $B_{T}$ $=2.25 \mathrm{~T}$, and $I_{p}=350 \mathrm{kA}$ in TEXTOR. Variation of the launcher vertical angle from $0^{\circ}$ (solid red line) to $25^{\circ}$ dashed red line) gives access to the $q=1.5$ to $q=3$ surfaces. The horizontal black bar indicates the size of a large $(10 \mathrm{~cm}) m=2, n=1$ island.

tearing modes on the $q=2$ and $q=1.5$ surfaces, respectively. Also control of sawteeth is considered, which requires localization of ECCD near the $q=1$ surface.

TEXTOR is a medium sized tokamak with circular cross sections, major radius $R_{0}=1.75 \mathrm{~m}$, and minor radius $a=0.46 \mathrm{~m} .{ }^{11}$ Typical operational parameters are $B_{T}$ $=2.25 \mathrm{~T}$, and $I_{p}=350 \mathrm{kA}$. The typical electron temperature on the $q=2$ surface is $0.5-1 \mathrm{keV}$, while the typical rotation frequency of a $m=2, n=1$ island is several kilohertz. The ECRH system consists of two gyrotrons: a $140 \mathrm{GHz}, 800$ $\mathrm{kW}$, and $10 \mathrm{~s}$ pulse length gyrotron used for ECRH and ECCD, and a $110 \mathrm{GHz}$ gyrotron used exclusively for collective Thomson scattering. ${ }^{12}$ The two gyrotrons cannot be operated simultaneously, and only the $140 \mathrm{GHz}$ is used for magnetohydrodynamics (MHD) control. ${ }^{16}$ During a pulse the gyrotron frequency is stable within a range of about 100 $\mathrm{MHz}$. Transmission of the high power gyrotron radiation to the tokamak is through a fully quasioptical transmission line. Waves are injected from the low field side using a fast steerable mirror with two degrees of freedom. The horizontal injection angle can be changed from $-45^{\circ}$ to $+45^{\circ}$ for co- or counter-ECCD, while the vertical injection angle can be varied from $-30^{\circ}$ to $+30^{\circ}$ to cover effectively the entire poloidal cross section. Waves are injected in $X$-mode providing almost full absorption over a wide range of parameters. Figure 2 sketches the geometry of the plasma and the ECRH system for the typical plasma parameters given above. For these parameters, the ECR is on the high field side, and the ECW deposition can be changed from the $q=1.5$ to $q=3$ surfaces by variation of the vertical injection angle. At higher magnetic fields the $q=1$ surface can be accessed as well.

Fast transport along magnetic field lines results in a flattening of the temperature profile inside the magnetic island. This results in a perturbation of the temperature profile as a function of the minor radius as sketched in Fig. 3: when viewed across the island $O$-point a distinct flattening of the profile across the width of the island is observed, whereas a

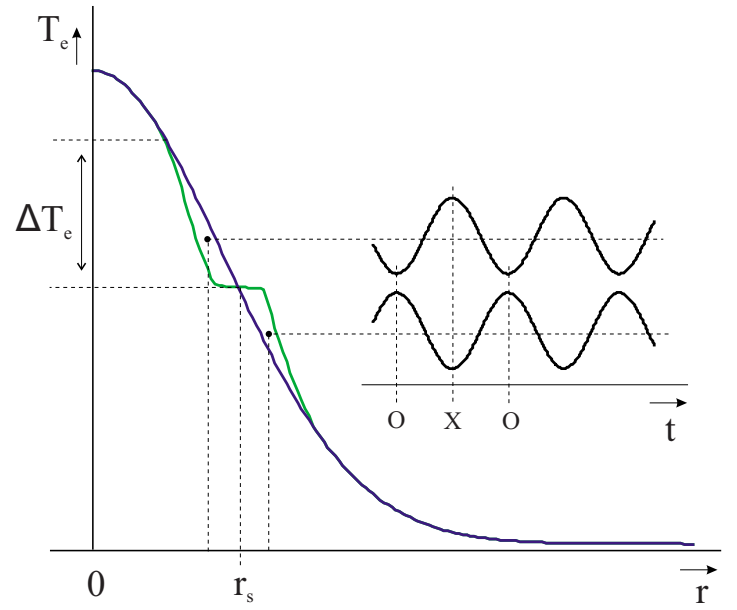

FIG. 3. (Color online) The effect of an island on the temperature profile. Fluctuations on ECE channels on either side of the island resonant surface indicate the presence of the island, and allow detection of $O$ - and $X$-points. On the left the perturbed electron temperature profile as observed through the $X$-point (blue curve) and as observed through the $O$-point (green). On the right two ECE channels as a function of time showing counter phase fluctuations (not to scale).

gradient is maintained when viewed across the $X$-point. Since the island is rotating with the plasma in front of the point of observation, this results in an almost sinusoidal perturbation of observed temperature as a function of time. This perturbation is characterized by a $180^{\circ}$ phase jump between signals on either side of the island. Such a phase jump between adjacent ECE channels can thus be used to determine the location of the island. The inset in Fig. 3 shows time traces of two ECE channels, the top channel is located at $r<r_{s}$ while the lower channel is located at $r>r_{s}$, where $r_{s}$ is the radius of the resonant surface where the island is located. This also shows how the $O$ - and $X$-point phases can be determined from ECE signals from opposite sides of $r_{s}$ : the signal from $r<r_{s}$ has a minimum at the $O$-point and a maximum at the $X$-point, and vice versa for the signal from $r>r_{s}$.

Stabilization of the island requires deposition of the ECW power inside the island. ${ }^{5-7}$ Consequently, the ECW power must be localized at $r_{s}$ with an accuracy of the radial deposition width which on TEXTOR may be as small as about $1 \mathrm{~cm}$. This then sets the required radial resolution for the ECE diagnostic to $\Delta R=1 \mathrm{~cm}$. The variation in ECE frequency as function of major radius can be estimated by $\Delta f / \Delta R=-f_{\text {gyr }} / R_{0}=-800 \mathrm{MHz} / \mathrm{cm}$, such that the required ECE channel spacing becomes $800 \mathrm{MHz}$. As overlap of ECE channels would reduce radial resolution and limit the minimum detectable island size unnecessarily, the intermediate frequency (IF) bandwidth $B_{\mathrm{IF}}$ of the ECE channels must be less than $800 \mathrm{MHz}$. However, lower bandwidth results in reduced signal-to-noise ratio and a compromise is set at $B_{\mathrm{IF}}=500 \mathrm{MHz}$. Ideally the full minor radius would be covered by the ECE diagnostic requiring a frequency span of $(a / \Delta R) \times \Delta f \approx 37 \mathrm{GHz}$. The minimum required span, however, would be about $12 \mathrm{GHz}$ covering, in about a third of the minor radius, the most relevant part of the plasma between the $q=1$ and $q=2$ surfaces (see Fig. 2).

The required signal-to-noise ratio from the ECE radiom- 
TABLE I. System requirements and theoretical system validation.

\begin{tabular}{lccc}
\hline \hline \multicolumn{1}{c}{ Parameter } & Required & Design & Comment \\
\hline Forward power & $800 \mathrm{~kW}$ & $800 \mathrm{~kW}$ & ok \\
Pulse length & $10 \mathrm{~s}$ & $3 \mathrm{~s}$ & - \\
Rejection ECW to ECE & $110 \mathrm{~dB}$ & $127 \mathrm{~dB}$ & ++ \\
Channel spacing & $800 \mathrm{MHz}$ & $3 \mathrm{GHz}$ & - \\
ECE span & $12 \mathrm{GHz}$ & $15 \mathrm{GHz}$ & + \\
IF BW & $500 \mathrm{MHz}$ & $500 \mathrm{MHz}$ & ok \\
Video BW & $10 \mathrm{kHz}$ & $10 \mathrm{kHz}$ & ok \\
$T_{r}$ radiometer & $5 \mathrm{kK}$ & $5 \mathrm{kK}$ & ok \\
Losses plasma to mixer & $12 \mathrm{~dB}$ & $17 \mathrm{~dB}$ & - \\
\hline \hline
\end{tabular}

eter is set by the relative fluctuation in the electron temperature caused by an island of the minimum size $w_{\min }$ that is to be detected and for which the phase is to be determined. This fluctuation is given by $\Delta T_{e} / T_{e}=w_{\min } / L_{T}$, where the temperature gradient length is given by $L_{T} \equiv T_{e}\left(r_{s}\right) / \nabla T_{e}\left(r_{s}\right)$. Equating the gradient length $L_{T}$ to the minor radius sets the minimum required signal-to-noise ratio level for the detection of a $1 \mathrm{~cm}$ magnetic island to $\mathrm{S} / \mathrm{N} \leq w_{\min } / a \approx 2 \%$. Observing fluctuations of $2 \%$ in the electron temperature at the $q=2$ surface at $1 \mathrm{keV}$ requires detection of ECE signal levels $\Delta T_{e}$ down to about $20 \mathrm{eV}$. The intrinsic thermal noise level in the ECE signal is given by the radiometer formula ${ }^{17}$

$$
\Delta T_{\mathrm{ECE}}=T_{e} \sqrt{\frac{2 B_{v}}{B_{\mathrm{IF}}}} .
$$

The video bandwidth $B_{v}$ is set to $10 \mathrm{kHz}$ in order to have sufficient temporal resolution in the case of island rotation up to $10 \mathrm{kHz}$. This results in a minimum detectable ECE fluctuation of $6.3 \mathrm{eV}$, or $73 \mathrm{kK}$. The noise in the overall receiver system should not exceed this limit. The overall receiver noise temperature is dominated by the product of the radiometer noise temperature with the total front-end losses. ${ }^{18}$ The required noise temperature of the radiometer has been set to $5 \mathrm{kK}$. The total front-end losses should therefore be less than a factor 15 , or $12 \mathrm{~dB}$.

This is all to be achieved in the presence of up to 800 $\mathrm{kW}$ of forward power from the gyrotron. In order to avoid compression in the radiometer the power level of stray radiation coming from the gyrotron should be reduced to levels comparable to the ECE radiation. The 15 orders of magnitude difference between the $800 \mathrm{~kW}$ gyrotron power and the $1 \mathrm{nW}$ in a typical ECE channel gives an impression of the enormous challenge faced here. The tokamak window is placed under a small angle in the transmission line in order to minimize reflection back into the line. However some reflected power, for example, from the plasma, is unavoidable, and the reflected gyrotron power is estimated at $100 \mathrm{~W}$ at the position of the in-line coupler for the ECE. The overall inline coupler must therefore reduce the gyrotron component by $110 \mathrm{~dB}$ with respect to the ECE component.

A summary of the requirements for the in-transmissionline ECE diagnostic for detection and control of tearing modes is given in Table I.

\section{DESIGN CHOICES AND REALIZATION}

The in-line receiver must perform two tasks. The first is to extract the ECE power coming from the plasma out of the quasioptical transmission line through which the high power ECW waves are transported toward the plasma. The second is the detection of the ECE power at selected frequencies. These two parts of the receiver will be discussed consecutively.

\section{A. Frequency selective directional coupler}

Monitoring of reverse power in an ECW transmission line is generally used to obtain an estimate of the total reflected gyrotron power. ${ }^{19}$ A basic technique to extract power from the transmission line is by small coupling holes in a miter band or mirror. A more sophisticated technique deploys a shallow grating to project a fraction of the overall beam toward a collection horn. The first method only provides a limited fraction of the Gaussian beam, and lacks frequency selectivity in the required band of interest. The grating arrangement does provide the overall beam profile and frequency selectivity, but the extracted frequencies are fanned out in space requiring individual front ends for each channel. Both methods have a fairly low coupling efficiency resulting in a huge reduction of ECE power.

In the present application, the frequencies of interest are the ECE frequencies and not the frequency of the high power gyrotron waves. This allows the use of a third option, a resonant dielectric plate placed under an angle in the transmission line, which combines frequency selectivity with a high coupling efficiency. The plate is based on the principle of resonant vacuum windows ${ }^{20,21}$ used in ECW installations. The transmission and reflection of such a plate are determined by the interference of multiple reflections from the two vacuum interfaces of the plate. These interfaces play the role of mirrors in a Fabry-Perot interferometer. ${ }^{22} \mathrm{~A}$ maximum in transmission at the gyrotron frequency is achieved by setting the thickness of the plate such that the optical path through the disk corresponds to a multiple of a $\frac{1}{2} \lambda_{\text {gyr }}$, where $\lambda_{\text {gyr }}$ corresponds to the wavelength of the radiation in the plate at the gyrotron frequency. Maxima in reflection occur at frequencies corresponding to odd multiples of $\frac{1}{4} \lambda_{\mathrm{gyr}}$. By placing the plate under an angle of $22.5^{\circ}$ and making it resonant at the gyrotron frequency a coupler is obtained that will pass the gyrotron component, but will reflect selected ECE frequencies under $45^{\circ}$ toward the receiver. The required plate dimensions follow from the location in the transmission line, the required channel spacing, the angle with respect to the ECW beam, and the material properties. The situation is sketched in Fig. 4.

General expressions for the reflection and transmission coefficients including losses in the plate are given below in the low loss limit ${ }^{20,21}$

$$
\begin{aligned}
& R(f)=\frac{R_{0 \perp}\left(1-2 L \cos (\varphi)+L^{2}\right)}{1-2 R_{0 \perp} L \cos (\varphi)+R_{0 \perp}^{2} L^{2}}, \\
& T(f)=\frac{L\left(1-2 R_{0 \perp}+R_{0 \perp}^{2}\right)}{1-2 R_{0 \perp} L \cos (\varphi)+R_{0 \perp}^{2} L^{2}},
\end{aligned}
$$




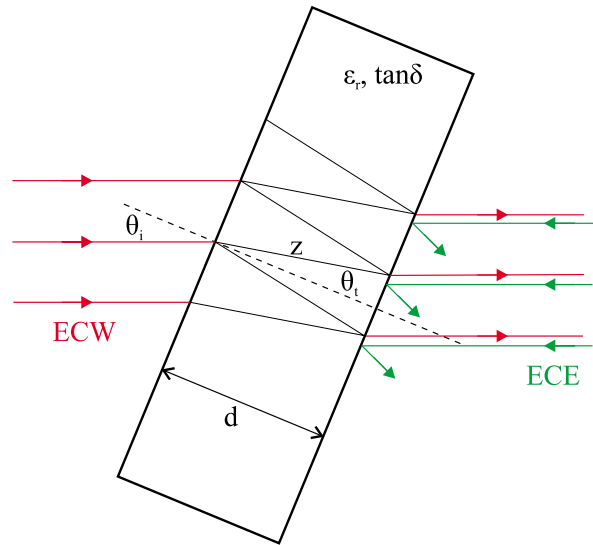

FIG. 4. (Color online) Principle of a dielectric plate as frequency selective coupling element. This case shows the plate under an angle of $22.5^{\circ}$. The reader can appreciate the ECW power incident from the left, and the ECE power from the plasma incident from the right. The ECW power is transmitted under a slight displacement of the beam, while a fraction of the ECE power (as determined by the reflection coefficient) is reflected away under $45^{\circ}$ toward a radiometer.

$$
A(f)=1-R(f)-T(f),
$$

$R(f)$ and $T(f)$ are the reflectivity and transmissivity, respectively, and represent the fractions of reflected and transmitted power of a uniform plane wave. $R_{0 \perp}$ is the square of the reflection coefficient on the vacuum-dielectric interface. Oblique incidence of the ECW beam and perpendicular polarization (perpindicular with respect to the plain of incidence, which is formed by the normal to the interface and the incoming ray) are used resulting in magnetic field components both normal and tangential to the interface. By requiring continuity of the tangential magnetic field component on either side of the interface the Fresnell reflection coefficient for perpendicular polarization is obtained: ${ }^{23}$

$$
\sqrt{R_{0 \perp}}=\frac{\eta_{1} \cos \theta_{i}-\eta_{0} \cos \theta_{t}}{\eta_{1} \cos \theta_{i}+\eta_{0} \cos \theta_{t}}
$$

The angles $\theta_{i}$ and $\theta_{t}$ are the angles of incidence and refraction, respectively, as indicated in Fig. $4, \eta_{0}=\sqrt{\left(\mu_{0} / \epsilon_{0}\right)}$ is the wave impedance in free space and $\eta_{1}=\sqrt{\left(\mu_{0} / \epsilon_{0} \epsilon_{r}\right)}$ is the wave impedance in the dielectric assuming nonmagnetic material. The phase shift between successive reflections is responsible for the resonances in reflection and transmission and is $\varphi=\left(4 \pi / \lambda_{1}\right) d \cos \theta_{t}$, with $d$ the thickness of the plate and $\lambda_{1}$ the wavelength in the dielectric. Finally, $L=\exp \left[-\left(2 \pi / \lambda_{1}\right) z \tan \delta\right]$ describes the decrease in power from absorption during a single pass through the dielectricum. Here, $z=d / \cos \left(\theta_{t}\right)$, and $\tan \delta$ is the loss tangent that is the ratio of the conduction current density over the displacement current density, i.e., $\left(\epsilon^{\prime \prime} / \epsilon^{\prime}\right)$ using the complex permittivity $\epsilon_{r} \equiv \epsilon_{r}^{\prime}-j \epsilon_{r}^{\prime \prime}$. Note that in the calculation of the reflection coefficient $R_{0 \perp}$ only the real part of the permittivity has been considered, which is safe in the low loss limit. The total absorbed fraction is $A(f)=1-R(f)-T(f)$ which, in the low loss limit, can be approximated by ${ }^{20}$

$$
A \approx \frac{\pi f z \tan \delta\left(1+\epsilon_{r}\right)}{c} .
$$

This is the general expression used in the assessment of low loss windows, and is independent of polarization and resonances in reflection or transmission.

The choice of material is motivated by optimizing transmission at the gyrotron frequency, which requires minimizing the absorption. For this reason, Infrasil301 ${ }^{\mathrm{TM}}$, a fused quartz, has been selected which has a particularly low loss tangent of $2.9 \times 10^{-4}$ (Ref. 24) in this range of frequencies and a permittivity of 3.805. In addition it has high homogeneity and low bubble content which minimize diffraction effects within the plate. By using Eq. (6) the absorption in the plate is found to be $2.0 \% / \mathrm{cm}$. The thickness of the plate also affects the minimum in reflection: a thicker plate means more absorption resulting in degraded interference and an increase in the minimum of reflection. An alternate choice of material would be chemical vapor deposited (CVD) diamond, which possess superior properties in terms of its extremely low loss tangent and high thermal conductivity, and is the preferred choice of material for the gyrotron and tokamak vacuum windows in high power ECRH systems. ${ }^{25}$ However, at the required thickness to achieve a minimum ECE channel spacing such windows are simply not available or would become excessively expensive.

In order to minimize the absorbed power density in the plate, it has been located near the largest waist along the gyrotron transmission line. This location is found approximately half way the transmission line where the waist is 97 $\mathrm{mm}$. At this location also sufficient space to install the support structure for the overall coupler is available. In order to cover $99.97 \%$ of the Gaussian beam a plate diameter of $4 \times w$ is required. Correcting for the plate angle of $22.5^{\circ}$, a diameter of $450 \mathrm{~mm}$ has been selected. The spacing between maxima in reflection is inversely proportional to the number of $\frac{1}{2} \lambda s$ that fit in the plate. At an incidence angle of $22.5^{\circ}$ a channel spacing of $800 \mathrm{MHz}$ would require a plate thickness of $98 \mathrm{~mm}$. However, this would amount to losses in the plate at an unacceptable level of $20 \%$. Therefore, a compromise was made by increasing the channel spacing to $3 \mathrm{GHz}$, which reduces the required thickness to $25.75 \mathrm{~mm}$, and reduces the losses to an acceptable level of 5\%. The reflected power fraction at the gyrotron frequency then becomes $-35 \mathrm{~dB}$. Figure 5 shows the reflected and transmitted fractions of power of the plate according to its final specifications.

Using the material properties of Infrasil301 ${ }^{\mathrm{TM}}$, the increase in the central temperature of the plate due to the power absorption is estimated at $50 \mathrm{~K} / \mathrm{s}$ in the case of an $800 \mathrm{~kW}$ gyrotron beam. The temperature increase causes a change in permittivity in quartz, ${ }^{26}$ which changes the resonance frequency. A temperature increase of $150 \mathrm{~K}$ is calculated to shift the resonance by $250 \mathrm{MHz}$, causing the reflection at the gyrotron frequency to increase from -35 to $-15 \mathrm{~dB}$. As a precaution the gyrotron pulse length has therefore been limited to $3 \mathrm{~s}$ at $800 \mathrm{~kW}$. At this rating, expansion and stresses resulting from the absorption in the plate were investigated using the finite element package ANSYS ${ }^{\mathrm{TM}}$. It was found that the maximum stress is $2.8 \mathrm{MPa}$, and is di- 


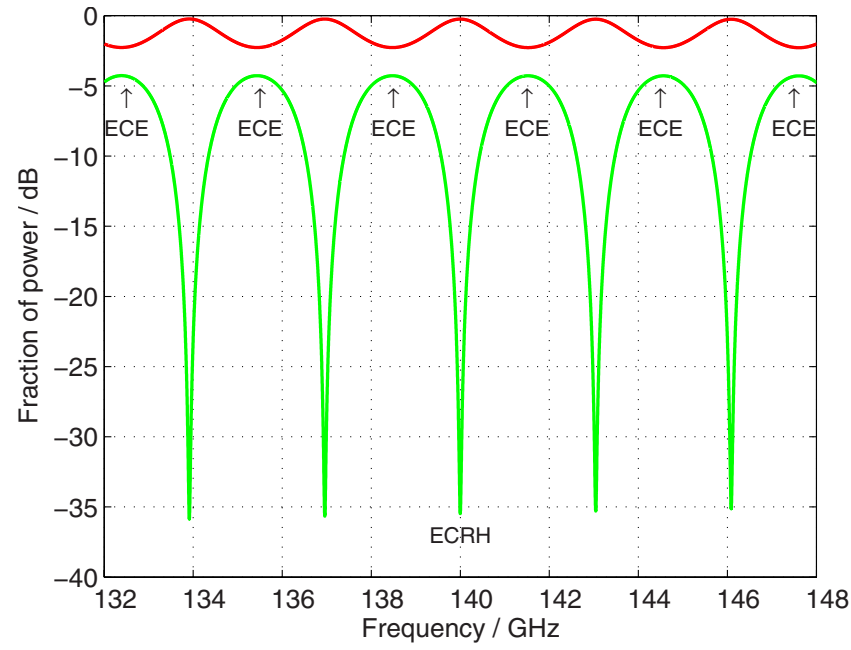

FIG. 5. (Color online) Fractions of transmitted (upper trace) and reflected (lower trace) power as a function of frequency using Eqs. (1) and (2) for a uniform plane wave (arrangement as shown in Fig. 4).

rected in tangential direction of the plate. The maximum allowable stress specified by the manufacturer is $50 \mathrm{MPa}$. The expansion of the disk was found to be in the order of $1 \mu \mathrm{m}$. This causes no significant deviation of the resonant frequency.

In the case of a uniform plane wave the amplitude of the multiple reflections is determined by the reflection coefficient, Eq. (5), and the losses. The gyrotron beam is not a uniform plane wave but has a Gaussian beam shape. With the beam at an oblique angle with respect to the plate this results in a shift of the maxima in the beam from subsequent passages through the plate, which will affect the interference. This effect is called walk-off ${ }^{27}$ and scales inversely proportional with the beam waist, and proportional with the offset between successive passages. The effect of walk-off was investigated using a computer model. The code sums the phase and amplitude of an arbitrary number of internal reflections. ${ }^{23}$ After summing four components, that is the initial reflected (or transmitted) ray followed by 3 round trip internal reflections, the reflected or transmitted fraction has converged to within $1 \%$ of the final result. This low number is a consequence of the relatively low permittivity, which gives rise to a low reflection coefficient [Eq. (5)], which, in turn, is squared to give the reflected fraction of power on a single reflection. After verification of the model with Eqs. (2) and (3) the code was adapted to take the Gaussian beam profile into account. The input beam was sampled with 450 points (1 mm spacing) and for each point of the reflected and transmitted profiles the first ten components of the multiple reflections were taken into account. The effect on the transmitted profile is found to be negligible, but in the minimum of reflection the reflected beam showed substantial distortion and, when integrated over the full beam profile, it is found that the reflected fraction increased from -35 to $-27 \mathrm{~dB}$. The effect on the maxima in reflection used for the ECE measurements is again negligible.

A reduction of $27 \mathrm{~dB}$ brings the estimated $100 \mathrm{~W}$ of reflected power from TEXTOR down to $200 \mathrm{~mW}$. In principle, a notch filter with an attenuation of $83 \mathrm{~dB}$ can now be

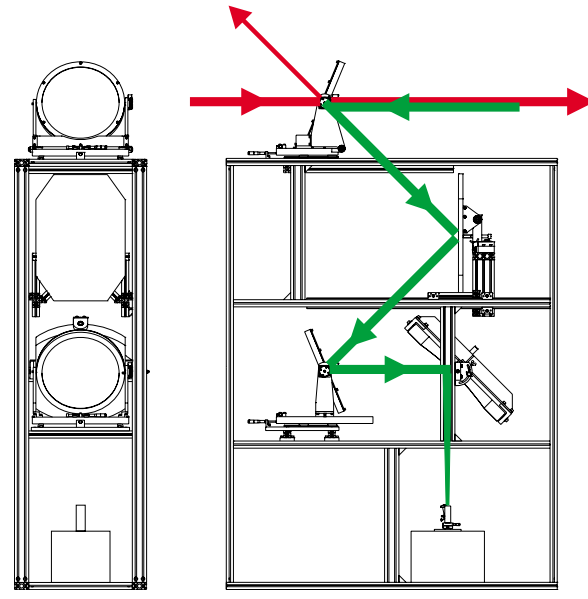

FIG. 6. (Color online) Layout of the coupler arrangement ("Optics Box"). To the right: the front view showing the optical components and the beam path of ECW and ECE. Note the ECW power reflected toward a water cooled microwave load (not shown here) on the left hand top corner. To the left: the side view of the box as viewed from the left.

used to achieve the required $110 \mathrm{~dB}$ attenuation in Table I, but an accidental increase in reflected power over a few orders of magnitude due to changing plasma conditions, would cause a breakdown in the notch filter. To avoid this, and to ease the burden on the notch filter, a second quartz plate has been included. This brings the gyrotron power before entering the notch filter down to fractions of a milliwatt. The overall coupler arrangement based on the two dielectric plates, a plane mirror, and a curved mirror to project the beam onto the horn antenna is shown in Fig. 6.

The total efficiency of the ECE transmission from the plasma to the radiometer horn is now estimated as follows. The path of the ECE power from the plasma via the launcher and through the CVD diamond window is estimated to cause an average loss of $1.0 \mathrm{~dB}$, the major part of this is due to the CVD diamond window not being resonant at the ECE frequencies. The signal is next relayed over four aluminum mirrors in the transmission line, and encounters two more aluminum mirrors in the coupler. The losses of these six mirrors are, using a conservative estimate, ${ }^{27}$ in the order of a percent and are therefore neglected. The maxima in reflection in Fig. 5 that theoretically can be achieved are not at unity $(0 \mathrm{~dB})$, but at $-4.3 \mathrm{~dB}$. Leaving a margin for the value that can be achieved in practice, the total reduction in power from the plasma to the horn antenna is therefore estimated at $11 \mathrm{~dB}$.

A fraction of at least $-27 \mathrm{~dB}$ of the ECW power incident on the first plate is reflected away upward. At $800 \mathrm{~kW}$ this still represents $1.6 \mathrm{~kW}$. A microwave dump has been installed at this location to absorb and monitor reflected power levels. The quartz plates and aluminum mirrors in the optics box are made fully adjustable to tune the plate angles to full transmission and to be able to couple the horn antenna precisely to the ECE beam. A corrugated horn was chosen to give low sidelobes in order to reduce pickup of stray radiation. The waist at the horn is $4.9 \mathrm{~mm}$, the half power bandwidth is at $8^{\circ}$.

\section{B. Radiometer}

The characteristics of the corrugated horn antenna were measured in the laboratory, and the parameters on the waist 


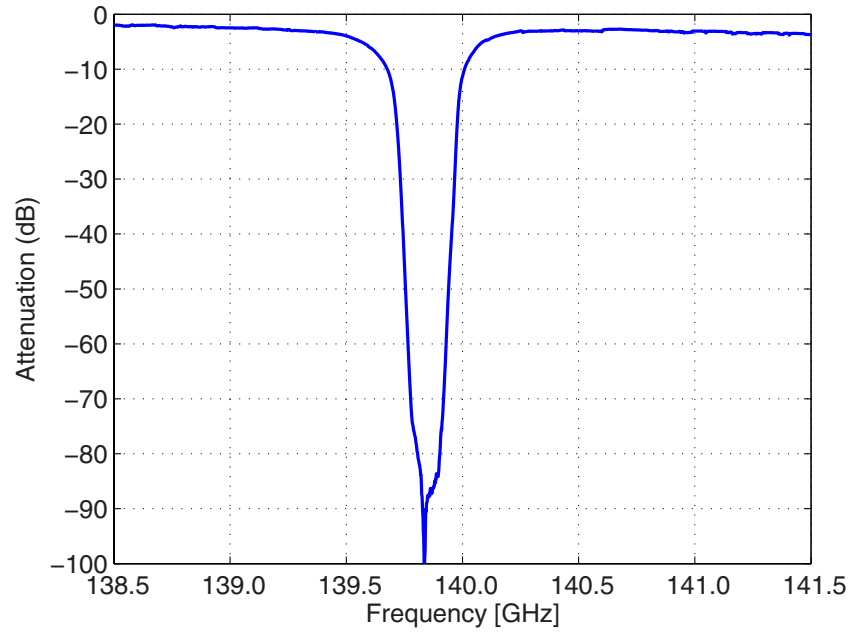

FIG. 7. (Color online) Notch filter tuned to exact gyrotron central frequency of $139.85 \mathrm{GHz}$. The reproducible depth of the notch, relative to the insertion loss, is approximately $80 \mathrm{~dB}$.

and the opening angle were used to optimize the curvature of the focusing mirror. The horn antenna is followed by an 80 $\mathrm{dB}$ notch filter with a bandwidth of $100 \mathrm{MHz}$, originally used in the collective Thomson scattering experiment at $\mathrm{JET}^{28}$ It was tuned in the laboratory to a minimum of $-80 \mathrm{~dB}$, at the gyrotron frequency, falling off to $-40 \mathrm{~dB}$ over a frequency shift of $100 \mathrm{MHz}$ (see Fig. 7).

Actual protection of the radiometer by the notch filter is only at the narrow notch, but during the rise time of the gyrotron beam current other modes will be excited resulting in ECW power at other frequencies. To protect the radiometer a $p-i-n$ switch has been included which switches $53 \mathrm{~dB}$ attenuation in circuit between the notch filter and the radiometer during the gyrotron switch on and switch off period. The waveguide components and radiometer are shown in Fig. 8.

The radiometer has been build to specification by Amtron Mikrowellentechnik (Bonn, Germany). It is a single

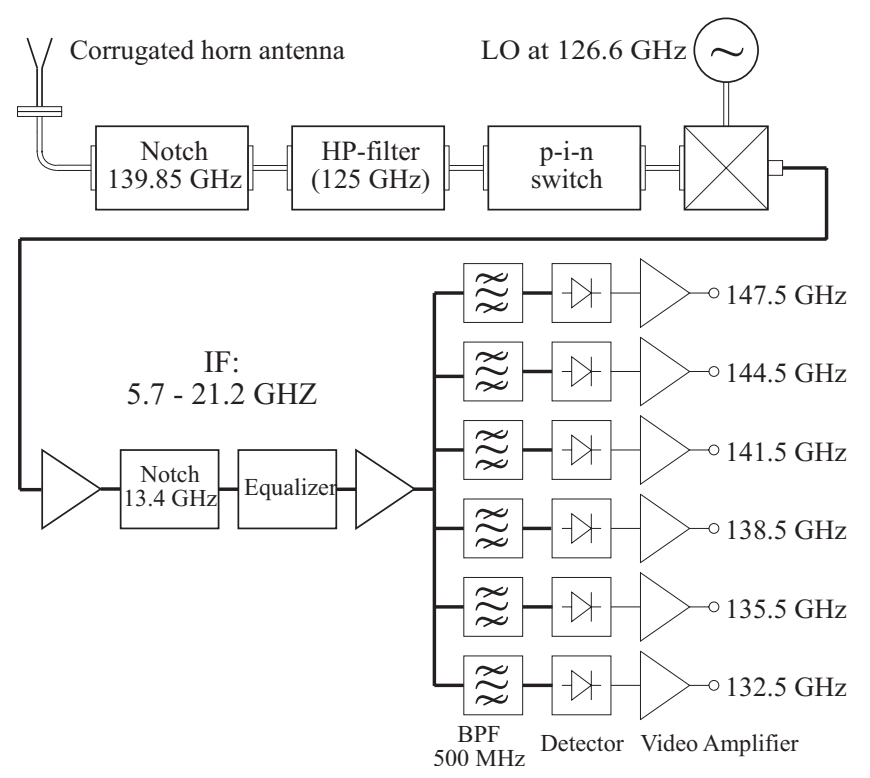

FIG. 8. Front-end and radiometer. side band heterodyne receiver with the $\mathrm{LO}$ at $126.6 \mathrm{GHz}$ and an IF band from 5.6 to $21.2 \mathrm{GHz}$. In the IF band an additional notch filter at $30 \mathrm{~dB}$ at the downshifted gyrotron component has been included, the total IF gain is $60 \mathrm{~dB}$. The six ECE frequencies start at $132.5 \mathrm{GHz}$, with $3 \mathrm{GHz}$ spacing and $500 \mathrm{MHz}$ bandwidth. The video bandwidth can be set to 1 , 10,100 , and $500 \mathrm{kHz}$. The average noise temperature of the six channels is $5000 \mathrm{~K}$, with the central channels having noise temperatures as low as $3600 \mathrm{~K}$. The coupling losses to the horn, loss of the notch filter, loss of the $p-i-n$ switch, and insertion losses are estimated to cause $6 \mathrm{~dB}$ losses from the horn to the mixer in the radiometer.

\section{Discussion of specifications and final design}

Table I compares the requirements of Sec. II with the predicted performance of the final design of the system outlined in this section. In comparison to the requirements, the maximum gyrotron pulse length is reduced to $3 \mathrm{~s}$ to avoid a too large shift of the notch in reflected power due to the temperature increase in the quartz. For application and demonstration of the scheme at TEXTOR this is not a serious problem. The rejection of the gyrotron component is better than required, which provides a comfortable margin in case the reflected fraction of ECW power from the plasma rises due to unforeseen effects. The channel spacing around the gyrotron frequency, set only by the plate thickness after selection of material and angle of incidence, has increased from $800 \mathrm{MHz}$ to $3 \mathrm{GHz}$ in order to limit the losses by absorption to $5 \%$. At the $140 \mathrm{GHz}$ resonance a $3 \mathrm{GHz}$ spacing corresponds to approximately a $3 \mathrm{~cm}$ radial resolution. This could compromise localization and suppression of islands with a full island width of less than $3 \mathrm{~cm}$. The overall losses from plasma to mixer are $11 \mathrm{~dB}$ (Sec. III A) +6 dB $(\mathrm{Sec}$. III B $)=17 \mathrm{~dB}$. The front-end losses are $5 \mathrm{~dB}$ too high, but recall that these losses were calculated to put the overall noise temperature below $6.3 \mathrm{eV}$, while $20 \mathrm{eV}$ is required for island detection. The overall receiver performance is expected to be sufficient.

\section{PERFORMANCE TESTS}

Manufacturing and assembly were done in stages allowing optimalization during the process. Low power microwave measurements on the quartz plate provided design details on accuracy and stability necessary for the adjustment mechanisms of the angle of the plate, and of the aluminum mirror adjustments. The optics box was assembled and padded with high grade eccosorb (VHP-2-NRL, EEMCOIMEX) to reduce stray radiation levels in the enclosure. It was than subjected to an overall low power acceptance test in the laboratory. The principal aim was to assess and minimize the reflected fraction of power at the gyrotron frequency, which implies automatically optimizing transmission at the gyrotron frequency. To this purpose a test rig with additional focusing mirrors was constructed which allowed illumination of the first quartz plate with a beam with identical quasioptical parameters as the ECW beam. The performance of the coupler was assessed with a network analyzer. The transmitter of the instrument was used to launch power from the 


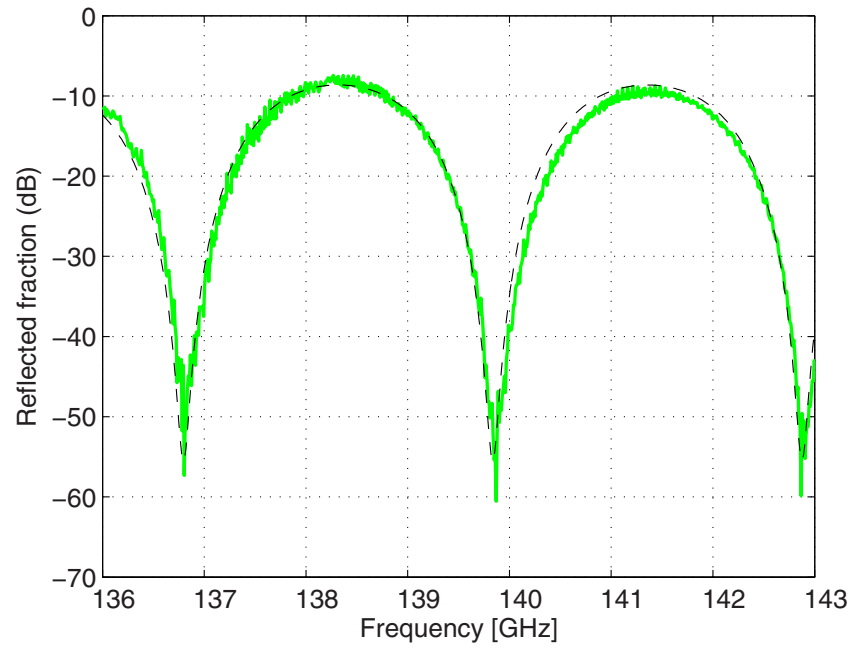

FIG. 9. (Color online) Verification of the fraction of reflected power as a function of frequency for the two plate arrangement. The solid green curve gives the measured response, the dashed black curve the response calculated with the model taking walk-off into account.

TEXTOR end while the receiver was mounted behind the horn antenna. The angle of incidence on the plates was set to $21.8^{\circ}$ to fine tune the notch to the exact gyrotron frequency of $139.85 \mathrm{GHz}$. The measurement was carried out in two stages. First the plates were covered with plane aluminum reflectors to obtain a $0 \mathrm{~dB}$ reference trace, next the measurement was repeated with the reflectors removed and the $0 \mathrm{~dB}$ reference trace subtracted. This is the green curve in Fig. 9. The dashed black trace is the two plate response calculated with the model. The expected $-27 \mathrm{~dB}$ attenuation per plate at the notches is achieved.

Next the optics box was installed and aligned in the TEXTOR bunker. A wooden diaphragm was mounted in the ECW transmission line with a diameter of $390 \mathrm{~mm}$ to avoid radiation in the tail of the Gaussian beam reflecting off the plate holder into the optics box. The gyrotron was set to 400 $\mathrm{kW}$ and fired onto the first quartz plate. The microwave dump arrangement above the optics box was used to tune the plate to minimum reflection. Using a caloric measurement the total absorbed power for a $1 \mathrm{~s}$ gyrotron pulse at $400 \mathrm{~kW}$ was found to be $700 \mathrm{~W}$, corresponding to a reflected power fraction of $-27.5 \mathrm{~dB}$. It should be noted that not all energy deposited in the microwave dump can be measured by the caloric measurement system, resulting in an underestimate of the reflected fraction. Heating up of the quartz plate was found to be $22 \mathrm{~K} / \mathrm{s}$ at $400 \mathrm{~kW}$. Both the number on the reflected fraction and the increase in plate temperature are in agreement with expected values. The tests were concluded by a measurement of stray radiation and reflected power while the gyrotron launched $400 \mathrm{~kW}$ of ECW power into the plasma. The power at the horn antenna was monitored and found to be fluctuating around $0.1 \mathrm{~mW}$, not exceeding 0.5 $\mathrm{mW}$ (see Fig. 10).

This level will be reduced by the notch filter by $80 \mathrm{~dB}$ resulting in power levels at the mixer below $10 \mathrm{pW}$, well below levels that would compromise detection of the ECE power.

The performance tests, and also the data presented in the

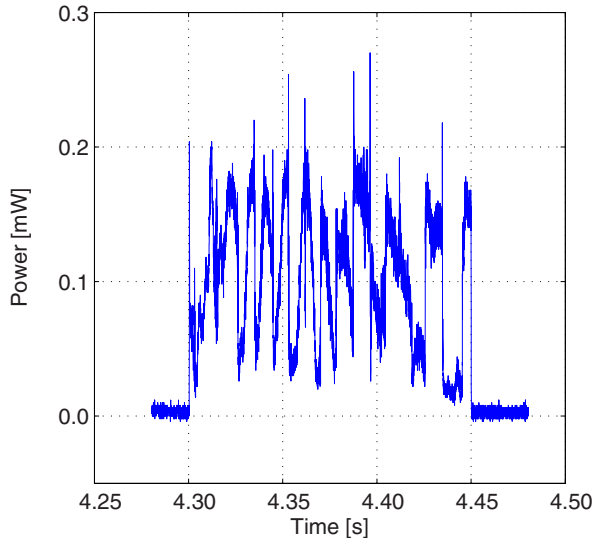

FIG. 10. (Color online) Measurement of stray radiation at the horn antenna during a $150 \mathrm{~ms}$ ECRH pulse at $400 \mathrm{~kW}$ (TEXTOR discharge No. 106235). The level is fluctuating around $0.1 \mathrm{~mW}$, not exceeding $0.5 \mathrm{~mW}$. The power at the radiometer mixer will be attenuated by an additional $80 \mathrm{~dB}$ by the notch filter.

following section, were all taken at $400 \mathrm{~kW}$. At $800 \mathrm{~kW}$ similar performance is expected, but different gyrotron $\mathrm{rf}$ output power levels generally cause a shift in gyrotron frequency requiring fine tuning of the gyrotron.

The alignment of the in-line receiver was verified by injecting microwave power at $138.5 \mathrm{GHz}$ into the horn antenna, and scanning the 2D Gaussian power profile at the TEXTOR window. The microwave alignment was found to be in good agreement with the laser alignment.

The noise temperature of the radiometer was verified in the laboratory by comparing the response to room temperature with $\mathrm{LiN}_{2}$, measured with a millivoltmeter. The measurements were taken directly at the input of the mixer and confirmed an average noise temperature of $5000 \mathrm{~K}$ for channels 1-5. Channel 6 gave a very poor result and the noise temperature could not be measured without reverting to signal averaging, not available at the time. The gain of channel 6 has been set extremely high in order to still use it in the experiments, but the data should be interpreted with care as it is prone to nonlinearity and cross-talk.

\section{FIRST ECE MEASUREMENTS DURING HIGH POWER ECRH}

Initial measurements were taken in the absence of ECRH to assess ECE performance of the receiver. Temperature traces were obtained on which structures such as sawteeth and island fluctuations can be clearly observed. Figure 11 shows data from TEXTOR discharge 106478.

The plasma current $I_{p}$ was $350 \mathrm{kA}$ and the toroidal field $B_{T}$ was $2.4 \mathrm{~T}$. The ECRH beam was injected under a vertical angle of $1^{\circ}$ (upward is positive) and a toroidal angle of $0^{\circ}$ (to the right is positive). At these angles and plasma parameters the ECE channels are located around the $q=1$ surface. The detailed view shows the inversion radius in the vicinity of channel 3 (138.5 GHz).

Data with combined ECE and ECRH are shown for discharge 106913 in Fig. 12.

Plasma conditions were $I_{p}=300 \mathrm{kA}, B_{T}=2.3 \mathrm{~T}$, and plasma density $n_{e}=2 \times 10^{19} \mathrm{~m}^{-3} .400 \mathrm{~kW}$ of ECRH was injected under a vertical angle of $1^{\circ}$, and a toroidal angle of $2^{\circ}$. 

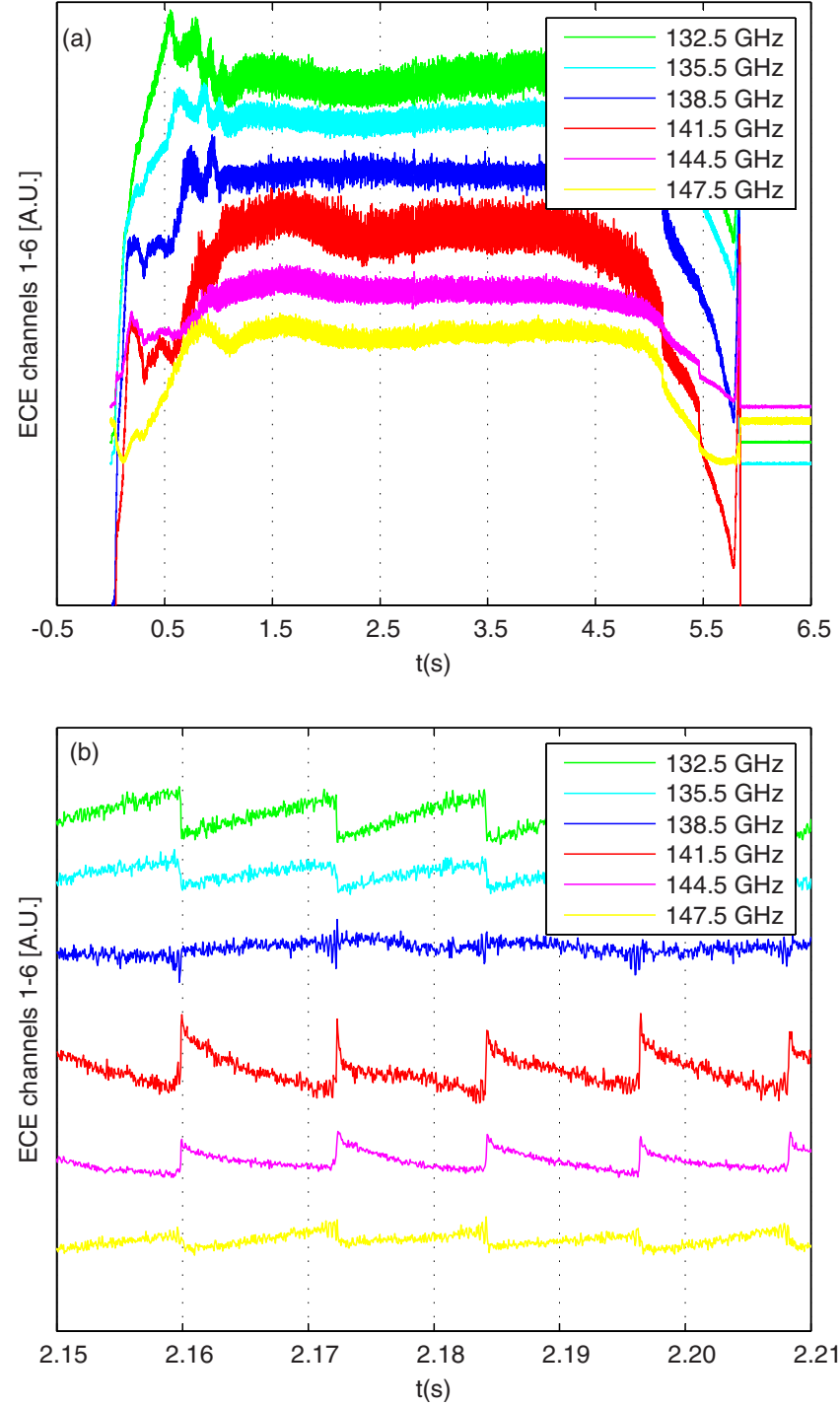

FIG. 11. (Color online) Line-of-sight receiver data for a pulse without ECRH, TEXTOR discharge No. 106478. Figure 11(a) shows the full discharge, and Fig. 11(b) a detailed view around $2.2 \mathrm{~s}$. The inversion radius on the $q=1$ surface is observed around channel 3. Cross calibration against Thomson scattering shows that the fluctuations of the precursor oscillations on channel 3 are in the order of $10 \mathrm{eV}$.

At these parameters the ECE channels are still approximately located symmetrically around the $q=1$ surface. The ECRH was applied between 2 and $4 \mathrm{~s}$ and the increase in electron temperature can be clearly observed in Fig. 12(a). A close up around $t=2.20 \mathrm{~s}$ in Fig. 12(b) shows the sawtooth inversion visible between the 132.5 and the $135.5 \mathrm{GHz}$ channels. The gyrotron power at $139.85 \mathrm{GHz}$ will therefore be deposited outside the $q=1$ surface. Theory predicts stabilization of the sawteeth in that case which indeed occurs after the gyrotron is switched on at $t=2.0 \mathrm{~s}$. When the ECRH is switched on the sawteeth are stabilized. A cross calibration of the data with Thomson scattering shows that features during ECRH, for example, the residual sawteeth on channel 2 at $2.01 \mathrm{~s}$, can be resolved down to $10 \mathrm{eV}$. This implies that the system requirements as defined in Table I are fulfilled.

The next measurement shows No. 107125 with combined ECE and ECRH in the presence of a tearing mode. Plasma conditions were $I_{p}=300 \mathrm{kA}, B_{T}=2.25 \mathrm{~T}$, and
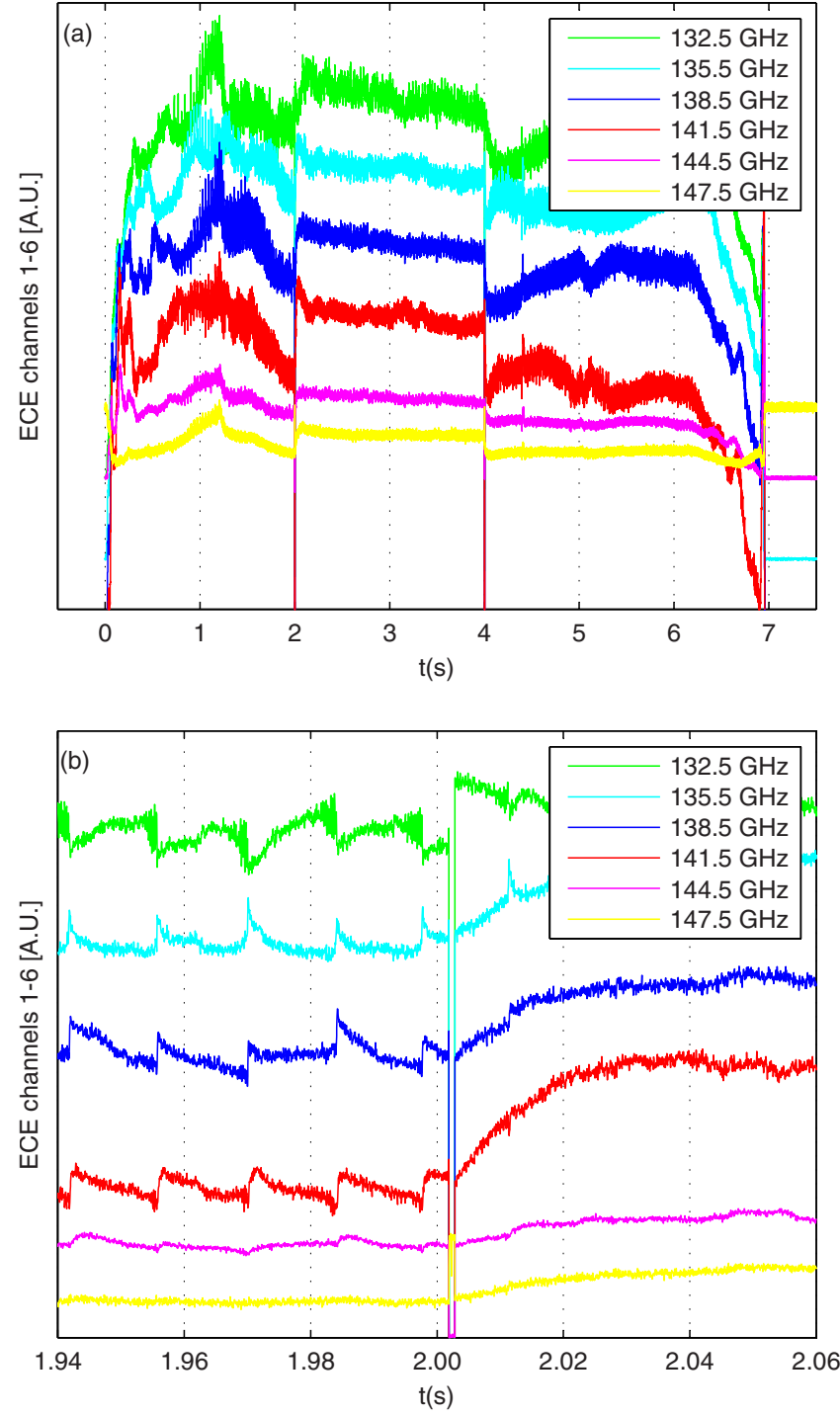

FIG. 12. (Color online) Line-of-sight receiver data with combined ECE and ECRH, discharge 106913. The effect of the heating on the ECE channels is observed (a), and sawteeth are suppressed at the moment the ECRH is switched on (b).

plasma density $n_{e}=2.5 \times 10^{19} \mathrm{~m}^{-3}$. The power was $400 \mathrm{~kW}$, injected at a toroidal injection angle of $-10^{\circ}$ corresponding to co-ECCD, and the vertical injection angle was varied from $-15^{\circ}$ to $15^{\circ}$ during the $2 \mathrm{~s}$ gyrotron pulse. Figure 13 shows a cross section of the plasma indicating the flux surfaces and ECE channel locations at the two extreme beam angles. As the beam is swept through the plasma the $140 \mathrm{GHz}$ resonance crosses the $q=2$ surface twice.

The overall discharge is shown in Fig. 14(a). For comparison an ECE channel at $141 \mathrm{GHz}$ from another radiometer at TEXTOR has been added to the plot. At $1.3 \mathrm{~s}$ into the discharge a $m=2, n=1$ island is formed. The detailed view in Fig. 14(b) at $1.5 \mathrm{~s}$ shows the fluctuations on the electron temperature caused by the rotating island. Phase reversal is observed between channels 132.5 and $138.5 \mathrm{GHz}$.

In Figs. 15(a) and 15(b) details are given of combined ECE and ECRH during the island phase. Figure 15(a) shows the period between switch on of ECRH and stabilization of the island near $200 \mathrm{~ms}$. Once the mode is stabilized as the 


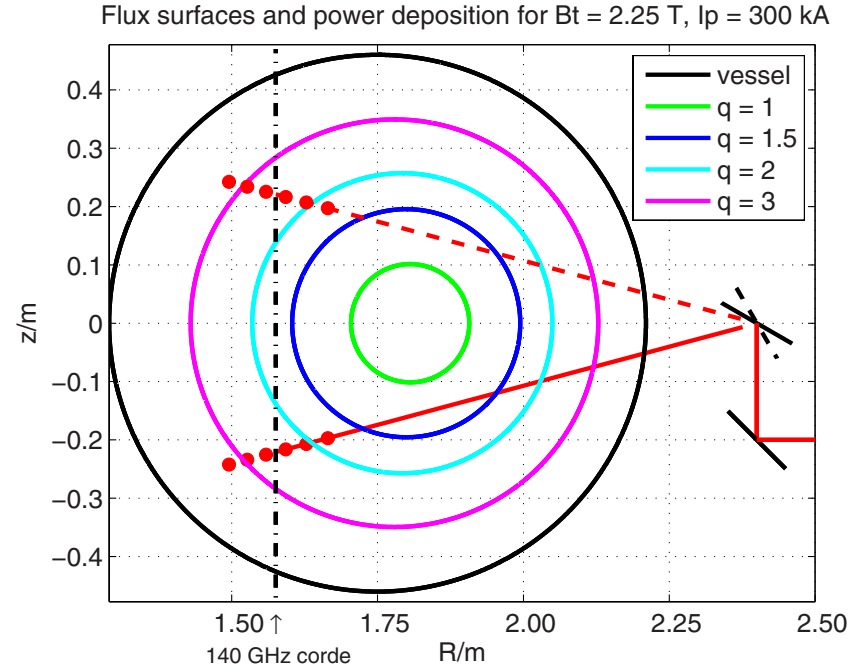

FIG. 13. (Color online) ECE channel location with the beam launched under a vertical angle of $-15^{\circ}$, and a vertical angle of $15^{\circ}$ for TEXTOR discharge No. 107125 .

heating has come close enough to the $q=2$ surface, the instability does not reappear as the heating again moves away from the $q=2$ surface. It also shows a large perturbation signal on the in-line receiver channels during the period that the island is present. Figure 15(b) shows the perturbed signals at a finer time resolution. It is seen that only during a particular period of time, fixed to the island rotation, the perturbation occurs. A close examination learns that the channel at $138.5 \mathrm{GHz}$ is fully saturated during this period, causing the response of the other in-line receiver channels to be compressed.

Perturbations are also seen at several degrees around perpendicular injection in discharges without rotating tearing modes.

\section{SUMMARY AND DISCUSSION}

The principle of a novel scheme to localize and suppress tearing modes using line-of-sight ECE has been demonstrated. In this scheme the high power ECRH transmission line is used in the reverse direction as an ECE receiver. By localizing a mode symmetrically at the gyrotron frequency it is ensured that the applied ECW in forward direction will be placed exactly on top of the mode. This paper has presented the design of the ECE receiver, and first results of measurements with the system as implemented on TEXTOR. Macroscopic MHD modes such as islands and sawteeth have been detected. It is shown that these modes can be localized in the ECE spectrum in the presence of $400 \mathrm{~kW}$ of forward ECW power. The minimum fluctuations in electron temperature that can be detected are in the order of $10 \mathrm{eV}$. This is satisfactory for the implementation of the receiver into a feedback system that is under development.

In some cases strong perturbations in the measured signals are observed during combined ECE and ECW. In the presence of an island a very high power level saturates the channel at $138.5 \mathrm{GHz}$ during a particular phase of the mode. This phase typically lasts $10 \%$ to $20 \%$ of the mode period time. During saturation the power level is so large that the
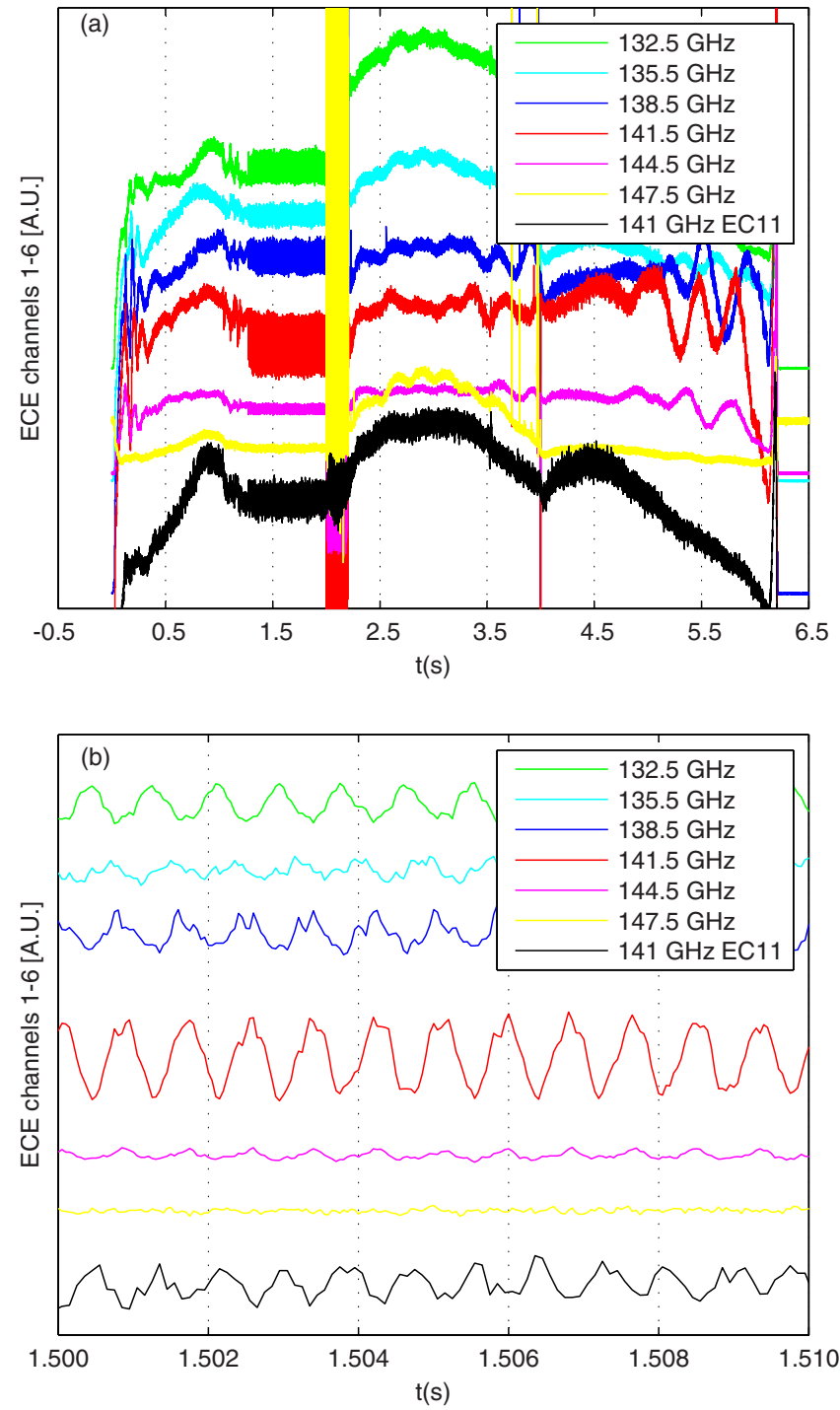

FIG. 14. (Color online) Combined ECE and ECW in the presence of an island, TEXTOR discharge No. 107125. (a) Overall plot. The black channel is a channel from a radiometer using another viewing line into the plasma. (b) Detail before switch on of ECRH.

radiometer goes into compression, forcing all other channels down. In case the ECW is launched perpendicularly the ECE measurements are perturbed in a similar way, without clear correlation to MHD activity. The mechanism causing these perturbations, probably from plasma physics origin, should be investigated for two reasons: in the first place because it is an unknown and intriguing phenomenon on itself and second because understanding might lead to measures to avoid the perturbations that sometimes could hamper the proper working of the feedback control system.

Work is ongoing to integrate the measurements into a feedback scheme to suppress tearing modes and control sawteeth. In the scheme the location of the mode will be derived from the characteristic $180^{\circ}$ phase jump between the ECE channels. This information is used to move the steerable launcher and control the gyrotron power and timing in order to stabilize the mode. The perturbations that occur in the combined presence of a mode and ECW may hamper algorithms used to detect and localize modes. 

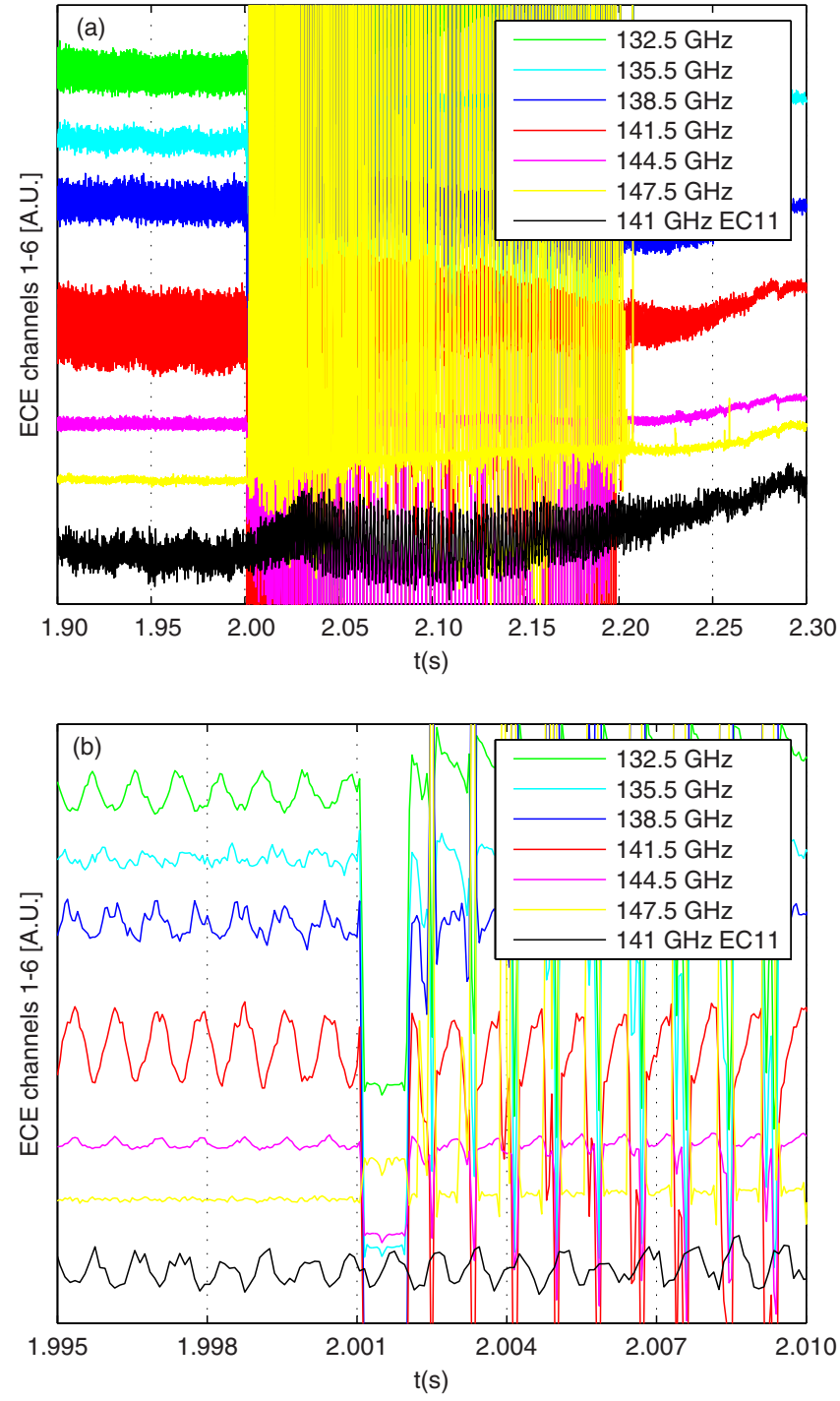

FIG. 15. (Color online) Suppression of the island in TEXTOR discharge No. 107125 occurs as the ECW beam is overlapping with the resonant surface (a). Viewed closely (b) the perturbations are in fact very large spikes occurring during a particular phase of the island rotation.

The presence and control of NTMs are a considerable challenge for safe and stable operation of ITER. ${ }^{29}$ The advantages of a line-of-sight scheme discussed in this paper, and the demonstration of ECE measurements in the presence of $400 \mathrm{~kW}$ forward ECW power, make it a promising addition to the tools for NTM localization and suppression in ITER. The present system, which has been designed for a quasioptical environment, has limited spatial resolution and limits the pulse length of the gyrotron. A Fabry-Perot etalon, two thin disks accurately separated by an air gap, might be a candidate to achieve a higher spatial resolution and a longer pulse length. The ECW installation in ITER does not use a quasioptical transmission line but waveguide transmission. Other possible implementations in a waveguide environment are currently under investigation as well. ${ }^{30}$

\section{ACKNOWLEDGMENTS}

The authors acknowledge the communications with Dr. J.A. Hoekzema on the problem of multiple reflections in quartz windows with losses. The authors are indebted to the designers, Mr. B. Lamers and Mr. F. van Amerongen, and to Mr. P. Wortman for assembling and installing the construction. The TEXTOR team is acknowledged for integration on TEXTOR and for experimental time. We thank Mr. R. Prins for his work on the caloric load. Mr. T. v/d Grift and Mr. G. Land provided support on the protection and control circuits of the instrument. We are grateful to Dr. A. Krämer-Flecken for helping out with spare microwave components during the 2008 campaign. Mr. B.C.E. Vaessen is acknowledged for the design and delivery of the data acquisition system of the instrument. This work, supported by the European Communities under the Contract of Association between EURATOM-FZJ, was carried out within the framework of the European Fusion Programme. The views and opinions expressed herein do not necessarily reflect those of the European Commission.

${ }^{1}$ J. Wesson, Tokamaks (Clarendon, Oxford, 1987).

${ }^{2}$ K. Ikeda, Progress in the ITER Physics Basis, Nucl. Fusion 47 (2007).

${ }^{3}$ O. Sauter, R. J. La Haye, Z. Chang, D. A. Gates, Y. Kamada, H. Zohm, A. Bondeson, D. Boucher, J. D. Callen, M. S. Chu, T. A. Gianakon, O. Gruber, R. W. Harvey, C. C. Hegna, L. L. Lao, D. A. Monticello, F. Perkins, A. Pletzer, A. H. Reiman, M. Rosenbluth, E. J. Strait, T. S. Taylor, A. D. Turnbull, F. Waelbroeck, J. C. Wesley, H. R. Wilson, and R. Yoshino, Phys. Plasmas 4, 1654 (1997).

${ }^{4}$ R. Prater, Phys. Plasmas 11, 2349 (2004).

${ }^{5}$ G. Gantenbein, H. Zohm, G. Giruzzi, S. Günter, F. Leuterer, M. Maraschek, J. Meskat, and Q. Yu, Phys. Rev. Lett. 85, 1242 (2000).

${ }^{6}$ A. Isayama, Y. Kamada, S. Ide, K. Hamamatsu, T. Oikawa, T. Suzuki, Y. Neyatani, T. Ozeki, Y. Ikeda, and K. Kajiwara, Plasma Phys. Controlled Fusion 42, L37 (2000).

${ }^{7}$ C. C. Petty, R. J. La Haye, T. C. Luce, D. A. Humphreys, A. W. Hyatt, J. Lohr, R. Prater, E. J. Strait, and M. R. Wade, Nucl. Fusion 44, 243 (2004).

${ }^{8}$ M. Maraschek, G. Gantenbein, Q. Yu, H. Zohm, S. Günter, F. Leuterer, and A. Manini, Phys. Rev. Lett. 98, 025005 (2007).

${ }^{9}$ E. Westerhof, E. Farshi, J. A. Hoekzema, W. Bongers, O. G. Kruijt, J. W. Oosterbeek, and J. Scholten, Proceedings of the 13th Joint Workshop on Electron Cyclotron Emission and Electron Cyclotron Heating, 17-20 May 2004, edited by A. Litvak (Institute of Applied Physics/RAS, Nizhny Novgorod, Russia, 2005), p. 357.

${ }^{10}$ J. W. Oosterbeek, E. Westerhof, W. A. Bongers, W. A. Bongers, I. G. J. Classen, I. Danilov, R. Heidinger, J. A. Hoekzema, B. A. Hennen, M. F. Graswinckel, O. G. Kruijt, J. Scholten, C. Tito, and B. C. E. Vaessen, Fusion Eng. Des. 82, 1117 (2007).

${ }^{11}$ U. Samm, Fusion Sci. Technol. 47, 73 (2005).

${ }^{12}$ E. Westerhof, J. A. Hoekzema, G. M. D. Hogeweij, R. J. E. Jaspers, F. C. Schüller, C. J. Barth, H. Bimdslev, W. A. Bongers, A. J. H. Donné, P. Dumortier, A. F. van der Grift, D. Kalupin, H. R. Koslowski, A. KrämerFlecken, O. G. Kruijt, N. J. Lopes Cardozo, H. J. van der Meiden, A. Merkulov, A. Messiaen, J. W. Oosterbeek, P. R. Prins, J. Scholten, V. S. Udintsev, B. Unterberg, M. Verier, and G. van Wassenhove, Fusion Sci. Technol. 47, 108 (2005).

${ }^{13}$ K. H. Finken, Fusion Eng. Des. 37, 337 (1997), Special issue on Dynamic Ergodic Divertor, edited by K. H. Finken.

${ }^{14}$ A. Merkulov, F. C. Schüller, E. Westerhof, M. R. de Baar, A. KrämerFlecken, and Y. Liang, Proceedings of the Joint Varenna-Lausanne International Workshop on Theory of Fusion Plasmas, Varenna, Italy, 30 August-3 September, 2004, edited by J. W. Connor, O. Sauter, and F. Sindoni (Societa Italiana di Fisica, Bologna, 2004), p. 279.

${ }^{15}$ C. Angioni, T. P. Goodman, M. A. Henderson, and O. Sauter, Nucl. Fusion 43, 455 (2003).

${ }^{16}$ E. Westerhof, A. Lazaros, E. Farshi, M. R. de Baar, M. F. M. de Bock, I. G. J. Classen, R. J. E. Jaspers, G. M. D. Hogeweij, H. R. Koslowski, A. Krämer-Flecken, Y. Liang, N. J. Lopes Cardozo, and O. Zimmermann, Nucl. Fusion 47, 85 (2007).

${ }^{17}$ H. J. Hartfuss, T. Geist, and M. Hirsch, Plasma Phys. Controlled Fusion 39, 1693 (1997).

${ }^{18}$ D. M. Pozar, Microwave Engineering (Wiley, New York, 2005).

${ }^{19}$ V. I. Malygin, V. I. Belousov, A. V. Chirkov, G. G. Denisov, and G. I. 
Kalynova, Conference Digest of the Twenty Seventh International Conference on Infrared and Millimeter Waves, San Diego, California, 22-26 September 2002 (unpublished), p. 299.

${ }^{20}$ H.-U. Nickel, "Hochfrequenztechnische Aspekte zur Entwicklung rückwirkungsarmer Ausgangsfenster für Millimeterwellengyrotrons hoher Leistung," Wissenschaftlichte Berichte, Forschungszentrum Karlsruhe, FZKA Report No. 5513, 1995.

${ }^{21}$ W. A. Bongers, "Millimetre-wave aspects of the FOM fusion free electron maser," Ph.D. thesis, TU/e Eindhoven, 2004.

${ }^{22}$ J. M. Vaughan, The Fabry-Perot Interferometer (IOP, Bristol, 1989).

${ }^{23}$ C. A. Balanis, Advanced Engineering Electromagnetics (Wiley, New York, 1986).

${ }^{24}$ R. Heidinger, Fusion Eng. Des. 66, 843 (2003).

${ }^{25}$ R. Heidinger, I. Danilov, A. Meier, B. Piosczyk, P. Späh, M. Thumm, W. Bongers, M. Graswinckel, M. Henderson, F. Leuterer, A. G. A. Verhoeven, and D. Wagner, Fusion Eng. Des. 82, 693 (2007).

${ }^{26}$ J. R. Birch, E. A. Nichol, D. V. Bartlett, and T. P. Hughes, The near millimetre wavelength optical constants of some potential window materials at elevated temperatures," JET-P Paper No. JET-P(94)46.

${ }^{27}$ P. F. Goldsmith, Quasioptical Systems (IEEE, New York, 1998).
${ }^{28}$ J. A. Hoekzema, H. Bindslev, J. Egedal, J. A. Fessey, C. P. Gatcombe, N. P. Hammond, T. P. Hughes, J. S. Machuzak, J. W. Oosterbeek, P. J. Roberts, A. L. Stevens, and P. E. Stott, Rev. Sci. Instrum. 68, 275 (1997).

${ }^{29}$ T. Hender, J. C. Wesley, J. Bialek, A. Bondeson, A. H. Boozer, R. J. Buttery, A. Garofalo, T. P. Goodman, R. S. Granetz, Y. Gribov, O. Gruber, M. Gryaznevich, G. Giruzzi, S. Günter, N. Hayashi, P. Helander, C. C. Hegna, D. F. Howell, D. A. Humphreys, G. T. A. Huysmans, A. W. Hyatt, A. Isayama, S. C. Jardin, Y. Kawano, A. Kellman, C. Kessel, H. R. Koslowski, R. J. La Haye, E. Lazzaro, Y. Q. Liu, V. Lukash, J. Manickam, S. Medvedev, V. Mertens, S. V. Mirnov, Y. Nakamura, G. Navratil, M. Okabayashi, T. Ozeki, R. Paccagnella, G. Pautasso, F. Porcelli, V. D. Pustovitov, V. Riccardo, M. Sato, O. Sauter, M. J. Schaffer, M. Shimada, P. Sonato, E. J. Strait, M. Sugihara, M. Takechi, A. D. Turnbull, E. Westerhof, D. G. Whyte, R. Yoshino, and H. Zohm, Nucl. Fusion 47, S128 (2007).

${ }^{30}$ W. Bongers, A. P. H. Goede, E. Westerhof, J. W. Oosterbeek, N. J. Doelman, F. C. Schüller, M. R. de Baar, W. Kasparek, W. Wubie, D. Wagner, and J. Stober, "Magnetic Island Localization for NTM Control by ECE viewed along the same optical path of the ECCD-beam," Fusion Sci. Technol. (submitted). 